\title{
Preferential Trade Agreements, Market Power, and Product Differentiation
}

\author{
Paul E. Jensen and Vibhas Madan \\ Drexel University
}

\begin{abstract}
Preferential trade agreements (PTAs) usually result in increased trade amongst member countries and lower prices within the PTA. Thus the markets are assumed to be "more competitive" because lower prices are taken to imply "decreased market power" due to a reduction in price-cost margins. In this paper we empirically examine the relationship between changes in market power and product differentiation within the context of a duopoly framework with restricted entry. Using industry level trade data from the EEC we show that the formation of a PTA may increase the market power of PTA-exporters and lower the market power of non-PTA exporters. In addition, we show that these market power effects are more pronounced for less differentiated products.
\end{abstract}

- JEL Classifications: F15, F12, L13

- Key words: Preferential trade agreements, Market power

\section{Introduction}

The US decision in the early 1980s to follow a "two-track" policy of trade liberalization which included a continued effort towards furthering multilateral agreements as well as pursuing new preferential trade agreements (PTAs) has resulted in an unprecedented worldwide increase in PTAs over the last two

\footnotetext{
*Corresponding address: Professor Paul E. Jensen, Department of Economics and International Business, Lebow College of Business, Drexel University, $32^{\text {nd }}$ and Chestnut Streets, Philadelphia, PA 19104. Tel: 215-895-2146, Fax: 215-895-6975, Email: jensenpe@drexel.edu, madanv@drexel.edu, Professor Vibhas Madan, Department of Economics and International Business, LeBow College of Business, 501 Matheson Hall, Drexel University, 32nd and Market Streets, Philadelphia PA 19104. Tel: 215-895-2124, Fax: 215-895-6975, E-mail: madanv@drexel.edu (C2004-Center for International Economics, Sejong Institution, All Rights Reserved.
} 
decades. In keeping with the increased economic importance of PTAs there has been a resurgence of empirical and theoretical research in this area. The insights provided in the seminal contribution by Viner (1950) are still at the core of much of the new analysis on PTAs. The central issues focus around the uncertain welfare effects of PTAs due to the "trade creation" and "trade diversion" effects. For a comprehensive analysis of the institutional issues as well as important advances in empirical and theoretical research in the area see Bhagwati and Panagariya (1996), Bhagwati, Greenway and Panagariya (1998), and Krueger (1999). Researchers in this area have explored a number of specific economic issues including the lowering of import prices, the loss of tariff revenues, increases in consumer welfare, static and dynamic welfare effects of PTAs, and more recently the dynamic welfare and political economy implications of PTAs. Grossman and Helpman (1995) and Krishna (1998) use political-economy constructs to show that trade diversion is an important motive leading to PTAs. An important element of any rent seeking argument and its welfare implications is the phenomenon of market power which is measured in its most basic form by price-cost margins. While studies which examine price changes and/or cost changes may allude to changes in market power they do not provide us with direct measures of changes in market power.

There is a well-developed body of work which looks at issues related to market power and international trade. Amongst others, Knetter (1989) examines exchange rate pass-through in the presence of imperfect competition, Aw (1992) examines the impact of restrictive trade policy and imperfect competition on price-cost mark-ups, Levinsohn (1993) examines the impact of international competition on domestic market power and Goldberg and Knetter (1999) examine the impact of exchange rate fluctuations on market power in export industries.

In this study we attempt to add to the literatures on "PTAs" and "market power and trade" by empirically examining the changes in market power associated with PTAs. Our specific objective is to try and isolate the impact of the level of product differentiation on changes in market power. Using cross-industry analysis, we examine the relationship between the market power effects of PTAs and the level of product differentiation by analyzing the percent changes in market power following a PTA.

Within the context of trade policy and in particular trade agreements such as PTAs the terms "increased competitiveness" and "lower prices" are seen as two sides of the same coin. The reason for this lies in the simple assertion that lower prices bring the prices closer to marginal cost and hence closer to the competitive outcome. The indirect implication is that the markets are more competitive not 
because of the lower prices per se but because of lower price-cost margins. When considering international trade it makes sense to interpret the cost in the price-cost margin framework somewhat differently than in a pure domestic market context. In particular, if we look at the total unit cost of selling in the importer's market then the cost for the exporter includes production costs as well as all trade costs including tariff payments and/or equivalent cost effects of other restrictive trade policies. Within this context the effect of a PTA is a discriminatory reduction in the unit costs for exporters within the PTA. The consequent change in the price-cost margin depends on the relative change in prices in response to lower costs. If liberalization does not induce significant entry of firms then under fairly standard assumptions regarding demand conditions and market behavior, it is seen that a lowering of export costs results in a less than proportionate decline in prices. Thus the price-cost margins for the exporters who experience the cost reduction are actually higher after the PTA. However, the price-cost margins of the non-PTA exporters will either go down or not change depending on the level of substitutability between the two products. ${ }^{1}$ Consequently, while it is clear that PTAs make the prices lower it is not clear that markets are more "competitive". Alternatively, we can restate this by saying that PTAs may increase the market power of the PTA exporters and reduce the market power of the non-PTA exporters and the magnitude of these effects will be conditioned by the level of product differentiation.

In Section 2 we develop a simple Cournot-duopoly model with product differentiation and no entry. Using a representative firm approach we show that the comparative-static effects of cost changes associated with PTAs are stronger for less differentiated industries. In Section 3 we use industry level trade data to examine the market power effects of the formation of the EEC. We estimate changes in residual demand elasticities that result from liberalization for countries exporting to EEC countries. We find that in some cases the PTA leads to increased market power for EEC members and that these increases are larger for goods that are more homogenous. It is also shown that decreases in market power for nonEEC exporters are larger for the more homogeneous industries. In Section 4 we summarize the analysis in this paper and indicate future research direction.

\footnotetext{
${ }^{1}$ In this paper PTA exports refer to intra-PTA exports and non-PTA exports refer to exports from non-PTA members into the PTA markets.
} 


\section{Cournot-Duopoly and Product Differentiation}

The scenario we are focusing on involves exporters selling a differentiated product in an imperfectly competitive market. This market is characterized by positive price-cost margins which depend on the cost and demand conditions. The main theoretical objective is to analyze the impact of a uniform cost reduction across a segment of exporters on the market power of all exporters and in particular to see how these effects are conditioned by the level of product differentiation. The specific issue we are looking at is one in which PTA exporters and non-PTA exporters are exporting their products to a common market within the PTA. The PTA agreement reduces the exporting cost for all the PTA exporters. ${ }^{2}$

Given that all the firms from the PTA region within an industry face a uniform cost reduction, due to lower intra-PTA trade costs, we only consider effects at the aggregate industry level and do not model the impact of within-group strategic interactions. Given this it makes sense to use a duopoly framework where for any given industry there is a PTA duopolist who sells total quantity $\mathrm{q}_{1}$ and competes with a non-PTA duopolist who sells $\mathrm{q}_{2}$.

We use a standard representative consumer approach to product differentiation and assume that expenditure on the differentiated product is a small proportion of total expenditure. This enables us to ignore income effects and lets us focus directly on the sub-utility function associated with the differentiated product. We assume that the outputs of the two firms enter symmetrically into the utility function which is given by:

$$
U(q)=\alpha\left(q_{1}+q_{2}\right)-\frac{1}{2}\left[\beta\left(q_{1}^{2}+q_{2}^{2}\right)+2 \theta q_{1} q_{2}\right]
$$

where all the parameters are positive and $\beta \geq \theta \geq 0$. This implies that the products are imperfect substitutes and that own effects dominate cross effects on demand.

If $\beta=\theta$ then the products are perfect substitutes and if $\theta=0$ then the products are independent. In this framework we are assuming that the number of firms is fixed and product differentiation is reflected purely by the level of similarity between existing products. Consequently, the level of product differentiation is exogenous and is inversely related to the parameter $\theta$. For a similar formulation

\footnotetext{
${ }^{2}$ For the sake of simplicity we do not model PTA and non-PTA exports to markets outside the PTA. There may be some interesting cross-effects in terms of reallocation of exports across markets by the exporters which may have an impact on the market power within the PTA
} 
see Singh and Vives (1984) and Vives (1999). This differs from the models of product differentiation which are in the Spence-Dixit-Stiglitz tradition where the central results are driven by a CES sub-utility function and free entry is typically assumed. ${ }^{3}$ Thus in the S-D-S approach the level of product differentiation is influenced by the level of substitutability as well as the number of varieties. Since the focus of our empirical analysis is to evaluate the comparative-static impacts of exogenous changes in product differentiation the quadratic sub-utility approach with no entry lets us isolate these impacts much more easily than a CES sub-utility approach with free entry. Utility maximization of (1) yields the following inverse demand system:

$$
P_{i}=a-\beta q_{i}-\theta q_{j} \quad i, j=1,2
$$

where $P_{i}$ is the price of the product sold by firm $i$ and $q_{i}$ and $q_{j}$ are the exports of the two duopolists into the PTA market.

Let $C_{i}$ represent the unit cost of exporting for firm i. We use $C_{i}$ as a catch-all term for all costs associated with exporting. This includes unit production costs $\mathrm{c}_{\mathrm{i}}$ and unit trade/transportation costs $t_{i}$ which can be viewed as a specific trade cost or a specific equivalent of an ad-valorem trade cost. Ignoring fixed costs, total cost of supplying the product to the import market for firm $i$ is given by:

$$
\left(c_{i}+t_{i}\right) q_{i}=C_{i} q_{i}
$$

Assuming that the unit costs are constant the profit functions are given by:

$$
\Pi_{i}=\left(P_{i}-C_{i}\right) q_{i}
$$

We further assume that the market is characterized by quantity competition and the firms behave non-cooperatively. Profit-maximization under these conditions yields the following first-order conditions:

$$
d \Pi_{i} / d q_{i}=a-2 \beta q_{i}-\theta q_{j}-C_{i}=0
$$

which in turn yields the following downward sloping reaction functions:

${ }^{3}$ See Spence (1976) and Dixit and Stiglitz (1977). 


$$
q_{i}=\left(\alpha-C_{i}-\theta q_{j}\right) / 2 \beta
$$

From (6) we can derive the Cournot-Nash equilibrium values $\left(\mathrm{q}_{1}{ }^{*}, \mathrm{q}_{2}{ }^{*}\right)$. The direct impact of a PTA is a decline in $t_{1}$ and from (3) we can see that for exogenously given levels of unit production costs $\mathrm{dt}_{1}=\mathrm{dC}_{1}$. Thus, we can analyze the comparative-static impacts of a PTA by looking at the changes in equilibrium in response to marginal changes in $\mathrm{C}_{1}$. Differentiating the equilibrium quantities with respect to $C_{1}$ we have (see Appendix for details):

$$
d q_{1}^{*} / d C_{1}<0 \text { and } d q_{2}^{*} / d C_{1}>0
$$

This implies that a reduction in exporting cost associated with the implementation of a PTA will increase the equilibrium exports of the PTA exporter and given the downward sloping reaction functions it will reduce the equilibrium exports of the nonPTA exporter. Differentiating (2) w.r.t. to $\mathrm{C}_{1}$ and using (7) we have:

$$
d p_{1}^{*} / d C_{1}>0 \text { and } d P_{2}^{*} / d C_{1}>0
$$

The implication is that a reduction in exporting cost associated with the implementation of a PTA will reduce the equilibrium price of both the PTA and the non-PTA exporter. The intuition behind this is that a decline in the cost of the PTA exporter increases the exports of the PTA exporter and the direct effect of this is to reduce the price for both the PTA and the non-PTA exporter. Furthermore the corresponding decline in the non-PTA exports will cause an increase in the prices of both exporters but this indirect effect is dominated by the direct effect.

The effect of the PTA on the market power of the two exporters can be evaluated by calculating the impact of a change in $\mathrm{C}_{1}$ on the price-cost margins of the two firms. We use the individual Lerner indices as a measure of market power and these are defined as:

$$
L_{i}=\left(P_{i}-C_{i}\right) / P_{i}
$$

Differentiating the Lerner indices with respect to $C_{1}$ we have:

$$
\begin{gathered}
d L_{1}^{*} / d C_{1}=-\left[P_{1}-C_{1}\left(d P_{1} / d C_{1}\right) /\left(P_{1}\right)^{2}\right]<0 \\
d L_{2}^{*} / d C_{1}=\left[C_{2}\left(d P_{2} / d C_{1}\right) /\left(P_{2}\right)^{2}\right]>0
\end{gathered}
$$


Equation (9) shows that as long as the price declines proportionately less than the cost of the PTA exporter, the market power of the PTA exporter increases. ${ }^{4} \mathrm{We}$ also see that the PTA has a negative impact on the market power of the non-PTA exporter as long as $\mathrm{dP}_{2}^{*} / \mathrm{dC}_{1}>0$.

The main objective of our analysis is to analyze how these cost pass-through effects are influenced by the level of product differentiation within a given industry. This influence can be studied by focusing on the impact of changes in $\theta$ on magnitude of the comparative static results we have stated in (7), (8), and (9). Differentiating (7), (8) and (9) with respect to $\theta$ gives us:

$$
\begin{aligned}
& d^{2} q_{1}^{*} / d C_{1} d \theta<0 ; d^{2} q_{2}^{*} / d C_{1} d \theta>0 \\
& d^{2} P_{1}^{*} / d C_{1} d \theta<0 ; d^{2} P_{2}^{*} / d C_{1} d \theta>0 \\
& d^{2} L_{1}^{*} / d C_{1} d \theta<0 ; d^{2} L_{2}^{*} / d C_{1} d \theta>0
\end{aligned}
$$

As noted earlier a higher (lower) $\theta$ corresponds to a lower (higher) level of differentiation in the industry. From (10) we see a decline in costs due to the PTA has a stronger upward effect on the exports of the PTA exporter and a stronger downward effect on the exports of the non-PTA exporter if the products within an industry are less differentiated. In other words, the cost advantage which results from a PTA has much stronger quantity effects when the products are more similar. The intuition is that the PTA exporter's marginal profitability of increasing sales in response to an exogenous cost reduction is higher if the non-PTA firm is selling a product which is a closer substitute.

The set of relationships in (11) tell us that the cost advantage due to the PTA results in a smaller decline in the price of the PTA exporter and a larger decline in the price of the non-PTA exporter if the products are less differentiated. The intuition is that any expansion in sales will be associated with a smaller decline in prices if the two products are closer substitutes. In other words, the price does not have to be lowered too much to increase sales if the products are similar. From the non-PTA firm's point of view, for any level of quantity it will have to have a more aggressive (lower) price if the products are closer substitutes. Hence, the

\footnotetext{
${ }^{4}$ This condition is satisfied for our model and for other formulations where the demand structure is not too convex.
} 
downward impact on its price is much stronger when the products are less differentiated and the PTA exporter expands its sales in response to a cost reduction.

The market power relationships in (12) indicate that lower export costs due to the PTA cause a greater increase in market power of the PTA exporter and a greater decline in the market power of the non-PTA exporter when the products are less differentiated. As noted above a decline in the cost of the PTA exporter is associated with a smaller decline in its price if the products are less differentiated. This implies that the lower cost is associated with a relatively larger increase in the price-cost margin if the products are closer substitutes. Since the price decline of the non-PTA exporter is greater if the products are less differentiated and since it does not experience a decline in costs, its price-cost margin decline is relatively larger if the products are closer substitutes.

The main implication of these results is that without entry all PTA exporters should experience an increase in market power and all non-PTA exporters should experience a decline in market power. Furthermore, the percentage changes will be greater for homogeneous goods industries as opposed to industries with differentiated goods.

\section{Data and Empirical Model}

The theoretical model yields 3 basic results regarding the market power effects of liberalization: 1) market power for exporters within the PTA increases due to costs decreasing by more than prices 2) market power of firms outside the PTA falls because of lower prices 3 ) these market power effects are more pronounced for homogeneous goods. As noted earlier we do not model the entry of firms, which is likely to be important in practice. When trade barriers decrease within the PTA it may induce firms from within the PTA to enter new markets within the PTA. Entry of new firms may act to decrease the market power for firms already in those markets. In most markets, this entry effect might be regarded as the dominant effect as it is usually assumed in the literature that PTAs lead to more competitive markets. Thus, in general the market power effects of PTAs are ambiguous as liberalization may increase, decrease, or have no effect on markups depending on the size of the entry and cost reducing effects of liberalization. Therefore, what we hope to accomplish in the empirical analysis is to identify cases where the cost reducing aspect of a PTA dominates the entry effect thus 
leading to increased market power.

Our data contain bilateral trade flows for 21 OECD countries from 1961-1995. The data consist of quantities and unit values reported at the 4-digit SITC level. The trade data were obtained from the OECD. In addition, for these 21 countries we have annual data on exchange rates, GDP, and wage indices from International Financial Statistics.

Of the 21 countries, five (Belgium/Luxembourg, West Germany, France, Netherlands, and Italy) are original members of the EEC and constitute our "EEC" group. In addition, there are 5 countries (Australia, Canada, Japan, New Zealand, and the USA) that never joined the EEC or formed free trade agreements with the EEC and thus they comprise our "non-EEC" group. To examine the potential market power effects of free trade area formation we consider intra-EEC trade and trade between our EEC countries and our non-EEC countries. The distinction between the two groups is important because it provides us with a natural experiment. The original 5 EEC members signed a trade agreement in 1959 that established a tariff reduction schedule that achieved zero tariffs for intra-EEC trade by 1969. This agreement of course did not affect tariffs for our non-EEC group. Therefore, our data enables us to examine the different market power effects that result form this type of discriminatory liberalization.

The 11 OECD countries that are not in our EEC or non-EEC groups are countries that either joined the EEC or formed a free trade agreement with the EEC countries at some time after 1969. Although we do not estimate market power for these countries their data does play an important role in our estimation procedure. For each bilateral trade relationship we examine we need to consider the effect of other countries that also export to that same market and thus we exploit the data from all 21 countries in this regard. Our data on the 21 OECD exporters on average represents about $77 \%$ of total world exports to our 5 EEC countries and thus we are able to account for most of the interaction between exporters for the markets we consider.

Our empirical analysis builds on the work of Baker and Bresnahan (1988) and Goldberg and Knetter (1999). These papers both present methods for examining market power by estimating residual demand elasticities. One of the advantages of this approach is that, unlike in the direct estimation of mark-ups, it does not require data on marginal cost. To estimate residual demand elasticities one only needs to observe cost shifters for competing exporters. Baker and Bresnahan (1988) discuss the relationship between residual demand elasticities and Lerner 
indices and note that the two measures are very closely related in models of differentiated products. Goldberg and Knetter (1999) is particularly relevant because they consider estimating the residual demand elasticity faced by a group of exporting firms in a given import market, which is appropriate for our industry level trade data. Given that our goal is to measure changes in market power as a result of liberalization we extend the Goldberg and Knetter (1999) model slightly. We begin by presenting their basic estimation equation and discuss the intuition behind the method. We then describe the simple extension of the model.

Country i's inverse residual demand for exports of good $\mathrm{k}$ from country $\mathrm{j}$ in year $\mathrm{t}$ is given by:

$$
\ln P_{i j k t}=\alpha_{0}+\alpha_{1} \ln Q_{i j k t}+\alpha_{2} \ln G D P_{i t}+\alpha_{3} \ln Z_{i c k t}+\varepsilon_{i j k t}
$$

where $Z_{i c k t}$ is a vector of cost shifters for other countries (country j's competitors) that export to country $\mathrm{i}$, and $\varepsilon$ is an error term. With this $\log$ linear specification, $\alpha_{1}$ gives an estimate of the inverse of the residual demand elasticity. The intuition for this estimation equation is that changes in country j's costs obviously don't affect the residual demand country $\mathrm{j}$ faces but changes in competing exporting country's costs do. ${ }^{5}$

The cost shifters we use in our model are wages and exchange rates for competing exporters. Since a given exporter may have a number of competitors in any given market we construct a trade-weighted index of competitor's real wages for each exporter in each market. ${ }^{6}$ For each importer, i, we look at the total amount of goods imported in a given industry from the other 20 OECD countries in our sample. In all cases we consider there are multiple exporters. Thus to measure the change in competing exporters' wages, we construct a variable that is the sum of all competitors' real wages weighted by the share of country i's imports coming from the respective competitors. Constructing a similar index to measure changes in competitors' exchange rates is slightly more complicated because the units of measurement on exchange rates differ across exporters. To solve this problem we construct a standardized exchange rate (a Z-score) for each country pair based on the mean and standard deviation of the exchange rate for the pair over the sample

\footnotetext{
${ }^{5}$ For a detailed discussion of the derivation of the residual demand curve see Goldberg and Knetter (1999).
}

${ }^{6}$ Note that all exporter wages are reported in the importing country's currency. 
time period. These standardized exchange rates are then used to construct a tradeweighted measure of competitors' exchange rates.

To measure changes in market power over time we introduce a dummy variable (DUM69) that indicates whether a given observation occurs before 1969. This dummy variable is interacted with the log of the quantity of imports to measure differences in the residual demand elasticity pre and post-liberalization. Thus, our estimation equation is given by:

$$
\begin{aligned}
& \ln P_{i j k t}=\alpha_{0}+\alpha_{1} \ln Q_{i j k t}+\alpha_{2} \ln G D P_{i t}+\alpha_{3} \ln W A G E_{i c k t}+\alpha_{4} \ln X R_{i c k t} \\
& +\alpha_{5} D U M 69\left(\ln Q_{i j k t}\right)+\alpha_{6} D U M 69+\varepsilon_{i j k t}
\end{aligned}
$$

With this specification $\alpha_{5}$ measures the difference in pre and post-liberalization residual demand elasticities. One econometric issue that must be addressed is that $Q_{i j k t}$ is endogenous. The endogeneity arises because $P_{i j k t}$ and $Q_{i j k t}$ are determined by demand and the profit-maximizing behavior of firms. Given this we use twostage least squares. For the residual demand equation to be identified we need at least one variable from the firm's supply relationship that is not an independent variable in the residual demand equation. The two supply variables we use are the exporter's wage and exchange rate.

Given that we have 35 years of data, equation 14 is estimated for every importerexporter-industry in our sample. ${ }^{7}$ After dropping observations with missing data and omitting cases with an insufficient number of observations, we obtained 5353 sets of estimates for equation (14) for intra-EEC trade and 2487 sets of estimates for trade between the EEC and non-EEC groups. Since our model predicts different effects for the EEC and non-EEC exporters we first examine the estimates for intraEEC trade and then consider the estimates for the exports from our non-EEC countries to the EEC importers.

Since the theory suggests that the level of product differentiation has implications for the size of the market power effects due to changes in trade barriers, we split our sample into homogeneous and differentiated goods cases. The classification of industries is based on Rauch (1999). Rauch classifies 4-digit SITC industries

\footnotetext{
${ }^{7}$ We did experiment with pooling the data and estimating a fixed effects model but this did not improve the quality of the estimates. In this application pooling presents a bit of a problem as the point to our paper is that the elasticities may vary across industries and trading partners and thus we do not want to impose restrictions regarding these estimates.
} 
based on the availability of prices for the goods. If there is an organized exchange for an industry with a standard price then the good is classified as homogenous. If there is not an organized exchange but reference prices can be located then the goods are somewhere between homogeneous and differentiated. If an industry does not even have reference prices then it is considered differentiated. Since there are many more differentiated industries, we treat the homogenous and referenced priced industries as being homogeneous industries.

Equation 14 is first estimated for the intra-EEC cases. Prior to estimating changes in market power it may be useful to examine the accuracy of estimates of the base level (pre-1969) market power which is captured by estimates of the inverse residual demand elasticity, $\alpha_{1}$. The t-statistics in Table 1 indicate that for $\alpha_{1} 99 \%$ of the estimates are reasonable in that they suggest a demand curve with a significant negative slope or a zero slope. However, when we look at the actual levels of the elasticity estimates shown in the lower half of table 1 , we see that the range is quite large and some of the numbers may raise questions about the

Table 1. Distributions for $\alpha_{1}$ Coefficients and $t$-Statistics

\begin{tabular}{|c|c|c|c|}
\hline \multicolumn{4}{|c|}{ Distribution of t-statistics for $\alpha_{1}$} \\
\hline & Percentiles & \multirow{5}{*}{ Obs } & \multirow{5}{*}{5353} \\
\hline $1 \%$ & -3.914822 & & \\
\hline $5 \%$ & -1.996492 & & \\
\hline $10 \%$ & -1.40821 & & \\
\hline $25 \%$ & -.6780007 & & \\
\hline \multirow[t]{2}{*}{$50 \%$} & -.0630145 & Mean & -.2010661 \\
\hline & & \multirow[t]{2}{*}{ Std. Dev. } & \multirow[t]{2}{*}{1.116828} \\
\hline $75 \%$ & .4141764 & & \\
\hline $90 \%$ & .9283574 & Variance & 1.247306 \\
\hline $95 \%$ & 1.250448 & \multirow[t]{2}{*}{ Skewness } & \multirow[t]{2}{*}{-2.250627} \\
\hline $99 \%$ & 2.075887 & & \\
\hline \multicolumn{4}{|c|}{ Distribution of estimates for $\alpha_{1}$} \\
\hline & Percentiles & & \\
\hline $1 \%$ & -53.67355 & & \\
\hline $5 \%$ & -11.16721 & & \\
\hline $10 \%$ & -4.585087 & \multirow[t]{2}{*}{ Obs } & \multirow[t]{2}{*}{5353} \\
\hline $25 \%$ & -1.138051 & & \\
\hline \multirow[t]{2}{*}{$50 \%$} & -.0942732 & \multirow{3}{*}{$\begin{array}{c}\text { Mean } \\
\text { Std. Dev. }\end{array}$} & \multirow{3}{*}{$\begin{array}{r}-.6732612 \\
72.79809\end{array}$} \\
\hline & & & \\
\hline $75 \%$ & 1.012938 & & \\
\hline $90 \%$ & 4.411955 & \multirow{3}{*}{$\begin{array}{l}\text { Variance } \\
\text { Skewness }\end{array}$} & \multirow{3}{*}{$\begin{array}{r}5299.562 \\
-11.08145\end{array}$} \\
\hline $95 \%$ & 10.36205 & & \\
\hline $99 \%$ & 55.67663 & & \\
\hline
\end{tabular}


accuracy of the estimates as they imply extremely inelastic demand. A plausible explanation for this may be the existence of a large unobserved domestic market. This may imply that our data are most appropriate where the domestic market is relatively unimportant. One would expect that exporter market power is more likely to exist in markets where domestic markets are less relevant. Consequently, it may be reasonable to condition on the existence of market power prior to 1969 $\left(\alpha_{1}\right.$ negative and significant). Table 2 shows the distribution of our statistically significant $\alpha_{1}$ estimates. The range of estimates in table 2 is much smaller and with a median value of -.6 the inverse residual demand elasticity estimates seem plausible. ${ }^{8}$ In addition, as expected, the percentage of differentiated goods cases indicating market power (8.8\%) exceeded the percentage of homogeneous goods cases $(5.9 \%)$.

Although not shown in our tables, we briefly discuss our estimates for the demand shifters GDP, competitor's exchange rate, and competitor's wage. The coefficient for GDP has the expected sign $66 \%$ of the time and the estimates are positive and significant at the $5 \%$ level $33 \%$ of the time. The median inverse income elasticity is .68 which might indicate the relative importance of manufactured as opposed to agricultural products in the sample. This is not surprising given the particular sample of countries in the data set.

The coefficient $\alpha_{4}$ measures the effect of a change in the competitor's bilateral exchange rate with the importing country on the exporter's price. This should be positive as an appreciation of the competitor's currency will increase the demand

Table 2. Distribution for $\alpha_{1}$ Coefficients Conditioned on Statistical Significance ${ }^{8}$

\begin{tabular}{rrrlr}
\hline & Percentiles & Smallest & & \\
\hline $1 \%$ & -4.717958 & -8.208305 & & \\
$5 \%$ & -2.606028 & -7.343651 & & 398 \\
$10 \%$ & -1.721913 & -6.354582 & Obs & 398 \\
$25 \%$ & -1.086411 & -4.717958 & Sum of Wgt. & -.9042146 \\
$50 \%$ & -.6355725 & & Mean & .9202854 \\
& & & Largest Std. Dev. & \\
$75 \%$ & -.3850618 & -.0895811 & & .8469253 \\
$90 \%$ & -.2415954 & -.077649 & Variance & -3.656464 \\
$95 \%$ & -.1799403 & -.0703683 & Skewness & 22.56142 \\
$99 \%$ & -.0895811 & -.0627703 & Kurtosis &
\end{tabular}

${ }^{8}$ Specifically, we only consider cases where the t-statistic on $\alpha_{l}$ in equation 14 is less than -1.65. 
for the exporter's product. Exchange rates appear to be a fairly good cost shifter as $\alpha_{4}$ has the correct sign $63 \%$ of the time and is significant $21 \%$ of the time at the $5 \%$ level. In addition the magnitude of the estimates appears reasonable as the median inverse elasticity is .2.

The coefficient on wage has the expected sign less the $50 \%$ of the time and thus it is not our most effective demand shifter. Since we have 2 cost shifters and neither is a primary variable of interest the fact that wage does not perform as well as one might expect should not affect our results.

Our main interest is to measure the changes in market power that may result from the PTA. Since our model has implications for the relative size of changes we are most interested in the percent changes in market power but first we will briefly comment on the absolute changes. As with our estimates of $\alpha_{1}$, the estimates of the absolute changes in market power, captured by $\alpha_{5}$ also seem reasonable. The majority of the estimates are positive suggesting that the entry effect of the PTA is the primary effect. The median value of $\alpha_{5}$ is .32 which seems reasonable. However, the most notable point is that a little more than $10 \%$ of the estimates are negative (of these $10 \%$, about half of the estimates are statistically significant), indicating an increase in market power. These increases occur when the cost effect from the PTA dominates the entry effect. ${ }^{9}$ It is also interesting to note some of the industries with statistically significant increases in market power resulting from liberalization. Some of theses industries are: Boxes and bags of paper and paperboard; Synthetic rubber; Acyclic alcohols and their derivatives; Printing paper in rolls or sheets; Aluminum and aluminum alloys, worked. These industries may be comprised mainly of goods produced in foundries, paper mills, and large chemical plants. If this is the case then the entry effect of liberalization may be small due to substantial fixed costs of production and thus the cost effect leads to increased market power. Similarly, many of the industries where there are significant decreases in market power are industries where fixed costs may be low and thus liberalization might lead to substantial entry effects. Some examples of these industries are: Prepared and preserved vegetables; Jams and fruit jellies; Bulbs of flowering plants; Manufactured articles of wood; Tableware and pottery; Nails and screws.

\footnotetext{
${ }^{9}$ It is important to point out that in the current application statistically insignificant estimates are meaningful as they imply that there is no change in market power. In addition, because $\alpha_{5}$ measures the net effect of the entry and cost effect, observing the $\alpha_{5}$ is zero does not necessarily imply that the cost effect is zero. Because of this we do not exclude statistically insignificant estimates.
}

${ }^{10}$ Coefficients are significant at the 5\% level. 
Given that we do not model or measure fixed costs of production in this paper we can't claim that this clearly demonstrates any connection between fixed costs and changes in market power. Nevertheless, the results seem to be suggestive in this regard.

To examine the percentage changes in market power we construct a variable $R$ $=\left(\alpha_{5} / \alpha_{1}\right)$. In Table 3 we report the summary statistics for the distributions of $\mathrm{R}$ for the homogeneous and differentiated sectors. Because we have conditioned on $\alpha_{1}$ being negative, a positive value of $\mathrm{R}$ means an increase in market power. As expected most cases are negative and this is probably due to the importance of entry effects which are not the focus of our analysis. However, we do find statistically significant cases where there is an increase in market power. This is indicative of the existence of situations where the negative market-power effect of entry is more than off-set by the positive market power effect of a discriminatory cost reduction. As can be seen from Table 3, the distributions are skewed and this

Table 3. Distributions for R Conditioned on Statistical Significance of $\alpha_{1}$

\section{Distribution of $\mathbf{R}$ for Homogeneous Goods}

\begin{tabular}{|c|c|c|c|}
\hline & Percentiles & & \\
\hline $1 \%$ & -2.53087 & & \\
\hline $5 \%$ & -1.561758 & & \\
\hline $10 \%$ & -1.300283 & Obs & 155 \\
\hline $25 \%$ & -.9589907 & & \\
\hline \multirow[t]{2}{*}{$50 \%$} & -.500971 & Mean & -.4312196 \\
\hline & & Std. Dev. & 1.755519 \\
\hline $75 \%$ & -.0197376 & & \\
\hline $90 \%$ & .7068502 & Variance & 3.081847 \\
\hline $95 \%$ & 1.079207 & Skewness & -1.689463 \\
\hline $99 \%$ & 3.254498 & & \\
\hline \multicolumn{4}{|c|}{ Distribution of $\mathrm{R}$ for Differentiated Goods } \\
\hline & Percentiles & & \\
\hline $1 \%$ & -2.576652 & & \\
\hline $5 \%$ & -1.513615 & & \\
\hline $10 \%$ & -1.188448 & Obs & 243 \\
\hline $25 \%$ & -.9018083 & & \\
\hline $50 \%$ & -.5457882 & Mean & -.4154696 \\
\hline & & Std. Dev. & .9150371 \\
\hline $75 \%$ & -.0623305 & & \\
\hline $90 \%$ & .5351476 & Variance & .837293 \\
\hline $95 \%$ & 1.031356 & Skewness & .8790696 \\
\hline $99 \%$ & 2.577259 & & \\
\hline
\end{tabular}


implies that a comparison of means is not very meaningful. Nevertheless, we can see that the distribution shifts slightly to the right for the case of homogeneous goods. We can see this by simply comparing the values of $\mathrm{R}$ from the $50^{\text {th }}$ to the $99^{\text {th }}$ percentiles. In addition, the skewness measures indicate that for homogeneous goods the observations tend to be concentrated in the right tail and for differentiated goods the observations are concentrated in the left tail. This is consistent with the theoretical prediction that the positive market-power effects of discriminatory cost reductions will be stronger for homogeneous goods.

We next examine how formation of the EEC affected our non-EEC exporting countries. For these exporters our model suggests that market power should decrease and that the market power effect should be more pronounced for homogeneous goods. For these exporters there were 1237 homogeneous goods cases and 1250 differentiated goods cases. As before, we condition on the existence of market power prior to liberalization and this leaves us with 118 cases. Our estimates of $\alpha_{1}$ and $\alpha_{5}$ once again seem quite reasonable as the median values were -1.09 and -.69 respectively. In addition, consistent with what one might expect, $96 \%$ of our $\alpha_{5}$ estimates suggest either a significant decrease in market power or no change in market power. In table 4 we report the distributions of the percent changes in market power for the differentiated and homogeneous goods industries. The table reveals that the median and mean values of $\mathrm{R}$ in the homogeneous sector are more negative than the corresponding values in the differentiated sector. This indicates that the decreases in market power are larger for the homogeneous goods sector. Thus, the results from the empirical analysis are consistent with the theoretical predictions which suggest that the market power effects of PTAs will be more pronounced for less differentiated products.

\section{Summary and Conclusion}

Research on PTAs has typically focused on the agreement's effect on prices and trade flows. Most research has shown that PTAs increase the intra-PTA volume of trade and lower prices for consumers. The intuition for this is that these agreements lower the cost for intra-PTA trade, which leads to lower prices for goods from within the PTA. In addition, this may also lead to price reductions for exporters who are not part of the PTA but compete with the PTA exporters within the PTA markets. The conventional thinking is that these lower prices imply that the markets are made more competitive by the PTA. In this paper we demonstrate 
Table 4. Distribution of $R$ Conditioned on Statistical Significance of $\alpha_{1}$

\begin{tabular}{|c|c|c|c|}
\hline \multicolumn{4}{|c|}{ Distribution of $R$ for Homogeneous Goods } \\
\hline \multicolumn{4}{|c|}{ Percentiles } \\
\hline $1 \%$ & -1.991088 & \multirow{4}{*}{ Obs } & \\
\hline $5 \%$ & -1.908196 & & \multirow{3}{*}{36} \\
\hline $10 \%$ & -1.2466 & & \\
\hline $25 \%$ & -.9559417 & & \\
\hline \multirow[t]{2}{*}{$50 \%$} & -.7071029 & Mean & -.6010902 \\
\hline & & Std. Dev. & .6753321 \\
\hline $75 \%$ & -.2423968 & & \\
\hline $90 \%$ & .4679137 & Variance & .4560735 \\
\hline $95 \%$ & .7089475 & Skewness & .1791794 \\
\hline $99 \%$ & .9478515 & & \\
\hline \multicolumn{4}{|c|}{ Distribution of $R$ for Differentiated Goods } \\
\hline & Percentiles & & \\
\hline $1 \%$ & -2.120819 & & \\
\hline $5 \%$ & -1.065472 & & \\
\hline $10 \%$ & -.9786778 & Obs & 82 \\
\hline $25 \%$ & -.8165661 & & \\
\hline \multirow[t]{2}{*}{$50 \%$} & -.5370355 & Mean & -.2911639 \\
\hline & & Std. Dev. & .9577142 \\
\hline $75 \%$ & -.144621 & & \\
\hline $90 \%$ & .6282043 & Variance & .9172165 \\
\hline $95 \%$ & 1.677084 & Skewness & 2.268689 \\
\hline $99 \%$ & 4.398053 & & \\
\hline
\end{tabular}

that this is not necessarily the case. It is usually assumed that the entry of firms induced by PTAs drives prices closer to marginal cost resulting in lower markups. However, we show that if the entry effects are weak then PTAs actually result in increased markups as prices decrease less than the cost of selling in the PTA. In addition we show that this markup-increasing cost effect is more pronounced for less differentiated goods. Using industry level trade data from the formation of the EEC we show that there is some empirical evidence for our theoretical predictions. We find that the formation of the EEC lead to more competitive import markets in most cases but for some cases liberalization actually lead to increased market power for the PTA exporters. Furthermore, as predicted by our model, the data suggests that the increases in markups were larger for the homogeneous goods. Similarly, we show that for non-member countries that export to the PTA countries, the decrease in market power is larger for the less differentiated goods.

In a static framework the fact that PTAs may result in increased markups may 
be of little practical significance. While recognizing that market power distortions may be growing as a result of liberalization may be interesting, the welfare improving effects of lower prices are likely to be more important. However, in a dynamic model the long-term welfare effects of a PTA may be influenced by changes in the level of market power. There are a number of long-term implications of increased market power (as measured by a higher price-cost margins) including the incentive for rent-seeking behavior and the ability of firms to effect entry of new firms. The final impact of the change in market power will be influenced by a number of factors including things such as entry and exit of new firms, policy responses by non-PTA exporter countries, the relative market share of PTA and non-PTA firms, reallocation of exports between the PTA and other markets outside the PTA by PTA and non-PTA exporters, just to name a few. Thus, in the long run PTAs could have welfare reducing effects if the increases in market power have adverse entry and exit effects. In future work we would like to examine this possibility more closely in a dynamic model with firm level data.

Received 1 May 2002, Accepted 26 October 2002

\section{Appendix}

Cournot-duopoly with linear demand and product differentiation

Given the quadratic utility function in (1), utility maximization yields the following demand system:

$$
p_{i}=\alpha-\beta q_{i}-\theta q_{j} \quad i, j=1,2
$$

The profit functions of the two dupolists are:

$$
\Pi_{i}=\left(p_{i}-C_{i}\right) q_{i}
$$

where $C_{i}$ is the total unit-cost of exporting into the importing country. The first-order conditions yield the following reaction functions:

$$
q_{i}=\frac{\alpha-\theta q_{j}-C_{i}}{2 \beta}
$$


The comparative-statics w.r.t. to changes in the unit exporting cost of the PTA exporter are given below $\left\{A=\left[1-\frac{\theta^{2}}{4 b^{2}}\right]\right\}$ :

$$
\begin{gathered}
\frac{d q_{1}^{*}}{d C_{1}}=\frac{-1}{2 A b}<0 \\
\frac{d q_{2}^{*}}{d C_{1}}=\frac{\theta}{4 A b^{2}}>0 \\
\frac{d p_{1}^{*}}{d C_{1}}=\frac{1}{2 A}\left[1-\frac{\theta^{2}}{2 b^{2}}\right]>0 \\
\frac{d p_{1}^{*}}{d C_{2}}=\frac{\theta}{4 A b}>0
\end{gathered}
$$

The sensitivity of the comparative-static results to changes in the level of product-differentiation is given by the following equations (for the sake of simplicity we look at the symmetric case where the cost parameters are same for both duopolists prior to the change in the costs of the PTA exporter):

$$
\begin{aligned}
& \left(\frac{d^{2} q_{1}}{d C_{1} d \theta}\right)=\frac{-(\theta / b)}{2 A b^{2}}<0 \\
& \left(\frac{d^{2} q_{2}}{d C_{1} d \theta}\right)=\frac{4 A b^{2}+2 \theta^{2}}{4 A b^{2}}>0 \\
& \left(\frac{d^{2} p_{1}}{d C_{1} d \theta}\right)=\frac{-\theta}{b^{2}}<0 \\
& \left(\frac{d^{2} p_{2}}{d C_{1} d \theta}\right)=\frac{4 A b+\frac{2 \theta^{2}}{b}}{(4 A b)^{2}}>0 \\
& \left(\frac{d^{2} L_{1}}{d C_{1} d \theta}\right)=\frac{2 p_{1} \frac{d p_{1}}{d \theta}\left\{p_{1}-C_{i} \frac{d p_{1}}{d c_{1}}\right\}-\left(p_{1}\right)^{2}\left\{\frac{d p_{1}}{d \theta}-C_{i} \frac{d^{2} p_{1}}{d C_{1} d \theta}\right\}}{\left(p_{1}\right)^{4}}<0 \\
& \left(\frac{d^{2} L_{1}}{d C_{1} d \theta}\right)=\frac{2 p_{1} \frac{d p_{1}}{d \theta}\left\{p_{1}-C_{i} \frac{d p_{1}}{d c_{1}}\right\}-\left(p_{1}\right)^{2}\left\{\frac{d p_{1}}{d \theta}-C_{i} \frac{d^{2} p_{1}}{d C_{1} d \theta}\right\}}{\left(p_{1}\right)^{4}}>0
\end{aligned}
$$


The sign of (A 12) and (A 13) depends on the sign of $\frac{d p_{1}}{d \theta}$, which can be shown to be negative for all relevant rages of $\theta$ as long as the market for the individual products is large enough.

\section{References}

Aw, B.Y. (1992), An empirical model of markups in a quality-differentiated export market. Journal of International Economics 33 (3/4), 327-344.

Baker, J., and Bresnahan, T., (1988), Estimating the residual demand curve facing a single firm. International Journal of Industrial Organization 6 (3), 283-300.

Bhagwati, J., Greenaway, D. and Panagariya, A., 1998. Trading preferentially: theory and policy. The Economic Journal 108 (July) 1128-1148.

Dixit, A., and Stiglitz, J., (1977), Monopolistic competition and optimum product diversity. American Economic Review 69, 961-963.

Goldberg, P.K., and Knetter M.M., (1999), Measuring the intensity of competition in export markets. Journal of International Economics 47, 27-60.

Grossman, G., and Helpman, E. 1995. The politics of free trade agreements. American Economic Review 85, 667-90.

Knetter, M., (1989), Price discrimination by US and German exporters. American Economic Review 79, 198-210.

Krishna, P., (1998), Regionalism and multilateralism: a political economy approach. The Quarterly Journal of Economics 113 (1), 227-251.

Krueger, A.O., (1999), Are preferential trading agreements trade-liberalizing or protectionist? Journal of Economic Perspectives 13 (4), 105-124.

Levinsohn, J., (1993), Testing the imports as market discipline hypothesis. Journal of International Economics 35 (1/2), 1-22.

Rauch, J. E., (1999), Networks versus markets in international trade. Journal of International Economics 48, 7-35.

Singh, N., and Vives, X., (1984), Price and quantity competition in a differentiated duopoly. Rand Journal of Economics 15, 546-554.

Spence, M. (1976), Product Differentiation and Welfare. Papers and Proceedings of the American Economics Review 66: 407-14.

Viner, J., (1950), The Customs Union Issue. New York: Carnegie Endowment for International Peace

Vives, X., (2000), Oligopoly Pricing: Old Ideas and New Tools. The MIT Press. 